\title{
The Interplay of Familial Depression Liability and Adverse Events in Predicting the First Onset of Depression During a 10-Year Follow-up
}

Petra Zimmermann, Tanja Brückl, Roselind Lieb, Agnes Nocon, Marcus Ising, Katja Beesdo, and Hans-Ulrich Wittchen

Background: The aim of the present article is to explore interaction and correlation effects between familial depression liability and selected adverse (separation and traumatic) events in predicting the first onset of a major depressive episode (MDE) in a 10-year prospective longitudinal community survey.

Methods: Analyses are based on 1982 subjects (14 to 24 years at baseline) without baseline MDE who participated during the whole study period and for whom diagnostic information about psychopathology in both parents was available. The offspring's familial depression liability was determined by aggregating information on parental depressive symptoms obtained from family history data and direct interviews with parents. Data were assessed with the Munich-Composite International Diagnostic Interview according to its DSM-IV algorithms.

Results: Adverse events predicted a substantially increased incidence of MDE among respondents with familial liability but not in those without familial liability. There was a significant interaction between familial liability and traumatic events with the strongest effect for the number of severe traumatic events (risk difference $=11.3 \%$; $95 \%$ confidence interval $=3.55-19.15)$. Associations with familial liability were most pronounced for separation events.

Conclusions: Adverse events are particularly pathogenic in individuals with familial liability. The involvement of interactions and correlations between familial liability and adversity might depend on type, severity, and number of events. Both processes are suggested to be concomitant rather than exclusive.

Key Words: Biological synergism, depression, depression liability, gene-environment interaction, trauma, vulnerability

The gene-environment interplay involved in the risk for unipolar depressive disorders is still an unresolved issue. While molecular-genetic studies select a specific candidate gene to investigate its interplay with environmental risks and restrict their findings to this specific gene (1-3), studies globally estimating existence, kind, and magnitude of a gene-environment interplay and dealing with the overall effects of genetic vulnerability on environmental pathogens are additionally important. These studies using twin and family data to indirectly determine genetic vulnerability are the focus of the present article.

Concerning a gene-environment interplay, three models have been described $(4,5): 1)$ independence of both factors, meaning that the impact of adversity on depression risk is similar in individuals with and without familial risk (additive effect of risk factors); 2) geneenvironment interaction or genetic control of sensitivity for stressful life events (effect modification, biological synergism); and 3) gene-environment correlation or genetic control of exposure to the environment (effect mediation). The validity of these relationship models has been examined predominantly in twin studies. Results from the Virginia Twin Study of 
Adolescent Behavioral Development (VTSABD) (6,7), the Cardiff Study of All Wales and North West of England Twins (CaStANET) (8), or the Virginia Twin Registry $(9,10)$ suggested gene-environment interactions regarding various stressful life events and adverse conditions. However, in line with the correlation model, twin studies also provide support that some adverse events and genetic risk are not independent (11-15).

The abovementioned relationship models also have been addressed in family studies but without having the possibility to separate genetic and shared familial environment influences. Most of them are high-risk studies (16-20) and/or based on clinical samples (16,18,19,21-23) with sample sizes ranging between 100 and 250 individuals. Few family studies are based on community data, larger samples size, and a cross-sectional design (24-26) and just one study has a prospective cohort design but the diagnosis of major depression and its age of onset are not prospectively assessed (27). Some of these studies provided evidence for the interaction model $(16,24,26)$ and some did not $(17,18,20,27)$. One study encouraged the correlation model (18), but others did not $(21,23)$.

To summarize previous research, there is an essential lack of studies based on representative community samples with a prospective follow-up. Findings from twin, high-risk, and clinical studies could be biased by sample selection and might not be representative for the community. While many studies, mostly those with adolescents, investigate depressive symptoms rather than clinical diagnoses $(24,26)$, studies with adults often do not separate between recurrent depression and the onset of a first episode $(10,18)$. Interplay processes vary depending on the kind of event (28). While a wide range of stressors has been examined, the explicit role of traumatic events in their interplay with familial vulnerability is still unclear. Many studies analyze ad-verse events in close temporal proximity to the onset of a depressive episode as a direct trigger $(6,10)$. Only a few studies investigate the medium and long-term impact of traumatic events on depression development, assuming that trauma exposure can induce a vulnerable phenotype $(29,30)$.

The present study explores various processes of interplay between familial depression liability and adverse life events in predicting the first onset of a major depressive episode (MDE). Highlighting the long-term impact of traumatic and separation events on depression development in a 10-year prospective-longitudinal community study based on a sample of 3021 individuals shall add important information to existing research.

\section{Methods and Materials}

\section{Design and Sample}

Data come from the prospective-longitudinal Early Developmental Stages of Psychopathology (EDSP) study comprising a baseline and three follow-up waves that cover a period of 10 years. Onset, persistence, and correlates of DSM-IV mental disorders are assessed in a community sample of adolescents and young adults in Munich, Germany. The baseline sample was drawn randomly from the 1994 government registries of residents aged 14 to 24 years in metropolitan Munich and surrounding counties. Due to a special interest in early stages of psychopathology, the 14- to 15-year-olds were sampled at twice and the 22- to 24-year-olds at half the probability of the individuals 16 to 21 years of age. A total of 3021 respondents were interviewed at baseline $(\mathrm{T} 0)$ (response rate $=71 \%$ ). The complete sample consists of white Europeans with German nationality. At baseline, almost three quarters of the participants were students, $36 \%$ at the secondary level and $26 \%$ at the university level. Twenty percent of the participants were employed. Sixty-two percent of the participants were 
living with their parents, $23 \%$ were living alone, and 12\% were living with their partner/spouse. Nearly all $(96.3 \%)$ were unmarried. The majority of the respondents belonged to the middle class $(59 \%)$ or upper middle class $(28.3 \%)$, reflecting the population of Munich.

The first follow-up (T1), on average 20 months after baseline, was conducted only for 14- to 17 -year-olds at baseline $(n=1228$; response rate $=88 \%)$, whereas the second and third follow-ups (T2, T3) were conducted for all subjects (T2: 42 months after baseline; $\mathrm{n}=2548$; T0-T2 response rate $=84 \%$; T3: $\sim 101$ months after baseline; $\mathrm{n}=2210$; $\mathrm{T} 0-\mathrm{T} 3$ response rate $=$ $73 \%$ ). The most frequent reasons for nonresponse at baseline or T3 were refusal/lack of time ( $21.5 \%$ and $17.7 \%$, respectively) and failure to contact (3.1\% and $8.3 \%$, respectively). Changes in sociodemographic characteristics between baseline and T3 occurred for school/employment status (T3: secondary school: .3\%, employed: $58 \%$ ) and living arrangements (T3: with parents: 12\%; with partner: 50\%). We did not find selective attrition between baseline and T3 due to age, gender, geographic distribution, major depressive episode (MDE), and adverse events, with two exceptions for individuals with divorced parents (odds ratio $[\mathrm{OR}]=1.2 ; 95 \%$ confidence interval $[\mathrm{CI}]=1.00-1.52 ; \mathrm{p}=.047$ ) and those exposed to violence $(\mathrm{OR}=1.6 ; 95 \% \mathrm{CI}=1.20-2.18 ; \mathrm{p}=.002)$. Detailed descriptions of the EDSP sample and design have been presented elsewhere $(31,32)$.

In the EDSP family supplement, direct diagnostic interviews were conducted with the mothers of the younger cohort (14- to 17-year-olds at baseline) $(33,34)$. Fathers were interviewed if the mother was dead or not locatable. Besides familial psychopathology, childhood information about the respondents was obtained $(n=1053: 1026$ mothers $/ 27$ fathers; response rate: $86 \%$ ).

The EDSP project and its family genetic supplement have been approved by the Ethics Committee of the Medical Faculty of the Technische Universitaet Dresden (No: EK-13811). All participants provided informed consent.

Analyses are based on 1982 respondents who completed T3, who did not fulfill lifetime criteria for MDE at baseline, and for whom diagnostic information about psychopathology in both parents was available (direct and/or family history information).

\section{Diagnostic Assessment}

Diagnostic assessment was based on the computer-assisted version of the Munich-Composite International Diagnostic Interview (DIA-X/M-CIDI) (35). The M-CIDI allows for the standardized assessment of symptoms, syndromes, and diagnoses of DSM-IV disorders along with information about onset, duration, and severity (36). Acceptable $(\kappa .4-.6)$ to good $(\kappa .6$ and higher) reliability and validity for the variables considered in the current investigation have been reported elsewhere (37-39). Highly trained clinical interviewers carried out the interviews face-to-face mostly in respondents' homes. The M-CIDI (lifetime version) was also used to assess diagnoses among parents in the direct interview.

Assessment of Separation and Traumatic Events. To assess lifetime separation events, death of a parent $(\mathrm{n}=108$ of total $\mathrm{N}=1982 ; 6.2 \%)$ and divorce of parents $(\mathrm{n}=470 ; 24.3 \%)$, MCIDI items at baseline were used (family history section). The category "any separation event" covers death and divorce in any parent $(\mathrm{n}=555 ; 29.1 \%)$.

Lifetime exposure to a trauma until baseline was assessed within the M-CIDI section for posttraumatic stress disorder. A list of seven traumatic event categories was presented. Items 
covered categories of 1$)$ war $(\mathrm{n}=5 ; .3 \%) ; 2)$ physical threat/violence $(\mathrm{n}=154 ; 8.1 \%) ; 3)$ rape $(\mathrm{n}=15 ; .9 \%) ; 4)$ sexual abuse as child $(\mathrm{n}=26 ; 1.8 \%) ; 5)$ natural disaster $(\mathrm{n}=7 ; .4 \%) ; 6)$ serious accident $(\mathrm{n}=126 ; 6.8 \%)$; and 7$)$ being kidnapped $(\mathrm{n}=2 ; .1 \%)$. The category "any trauma" comprises all traumatic events $(\mathrm{n}=297 ; 16.2 \%)$. The category "any severe trauma" only includes qualified traumatic events, defined as events that meet the DSM-IV A2 criterion; this means that respondents reported intense fear, helplessness, or horror on experiencing the respective traumatic event $(\mathrm{n}=224 ; 12.2 \%)$.

Exposure to any separation or traumatic event was indicated by the category "any adverse event" ( $(\mathrm{n}=745 ; 39.5 \%)$. Due to small case numbers, the presented results are based on aggregated event categories.

Assessment of Familial Depression Liability. To determine offspring's familial depression liability, broadly defined as presence of at least subthreshold parental depression, two sources of reported information were used.

First, family history items about first-degree relatives were developed according to a modified version of the Family History- Research Diagnostic Criteria (40). At baseline, to obtain family history information, M-CIDI stem questions for DSM-IV diagnoses were used and respondents were additionally asked whether the relative sought professional help because of the respective symptoms. At T2 and T3, an extended version of the family history module was applied that covers M-CIDI/DSM-IV-criteria. Second, parents of the younger cohort were independently assessed with the M-CIDI in the EDSP family supplement. Interviewers were blind to the diagnostic findings from offspring. The parent M-CIDI contained a module providing family history data also for the noninterviewed parent (33).

Offspring's familial liability for depression was defined by using all available diagnostic information about the occurrence of any major depressive episode in parents on an at least subthreshold level with either five depression symptoms (A criterion) with/without impairment or four symptoms plus the impairment criterion ( $\mathrm{C}$ criterion). This procedure was chosen due to a rather low sensitivity of family history information (see below). For parents of the older cohort, family history information from the respondent interview (T0, T2, T3) was used; for parents of the younger cohort, both the direct M-CIDI information and family history data from respondents and parents were used. The overall rate for familial depression liability in offspring in the present sample was $53.2 \%(n=1054$ of total $\mathrm{N}=1982)$.

To evaluate the accuracy of the family history information, the direct information from mothers was compared with data obtained from respondents about their mothers; the family history information obtained from respondents about their fathers was compared with the information about fathers given by mothers. Overall, only moderate sensitivity ( $48 \%$ for detection in mothers, $63 \%$ for detection in fathers) but acceptable to high specificity $(68 \%$ for mothers; $85 \%$ for fathers) were found for major depression (34).

Assessment of Major Depressive Episode and Other DSM-IV Mental Disorders in Offspring. Major depressive episode and other mental disorders used as control variables such as anxiety disorders (panic disorder with and without agoraphobia; agoraphobia without panic disorder; specific phobia; phobia, not otherwise specified; social phobia; generalized anxiety disorder; obsessive-compulsive disorder; and posttraumatic stress disorder) and substance use disorders (SUD) (alcohol abuse and dependence, nicotine dependence, and illicit drug abuse and dependence) were assessed with the DSM-IV/M-CIDI algorithms. Incident MDE was defined as meeting DSM-IV criteria for MDE for the first time during follow-up (T1-T3). 


\section{Statistical Analyses}

All associations were calculated with ORs based on logistic regressions.

To determine the biological synergism between familial liability and adversity on incident MDE, an additive statistical interaction model was used (41-43). Given the absence of any biases, a superadditive risk difference (RD) interaction (i.e., the combined effect of two factors exceeds the sum of their individual effects) indicates causal synergy at least in some individuals $(44,45)$. The $\mathrm{RD}$ has been proposed as an appropriate measure in terms of the standard models of causality (counterfactual causality and the sufficient component cause model) $(45,46)$. We used the BINREG procedure in the STATA software package (StataCorp., College Station, Texas) to compute RDs (47).

All analyses were performed twice: first, controlling for age and gender only, and second, additionally controlling for baseline anxiety and SUD. Control variables were chosen a priori guided by previous research (34).

Age-specific cumulative lifetime incidences for MDE were estimated with the Kaplan-Meier method (48) using age of onset information. This was done in four mutually exclusive groups defined by familial depression liability (with vs. without) and exposure to any adverse event prior to baseline (with vs. without). Few cases reported MDE for the first time at one of the follow-ups (T1, T2, T3) but dated the age of onset before their age at T0; as age of onset reports can easily be affected by recall biases even if a severe MDE had developed, we decided to put more weight on baseline reports and defined the age of onset for these cases as their age at baseline plus 1 year. Differences between the four mutually exclusive groups were tested with hazard ratios (HR) from Cox regression (stratified Cox regression) (48).

All data were weighted by age, gender, geographic location, noncontact and nonresponse at T0 to match the distribution of the original sampling frame (32). All statistical analyses were carried out with the STATA software package (49). The Huber-White sandwich method for weighted data was used to adjust statistical inference for the weighting of the data (50).

\section{Results}

\section{Association Between Familial Liability for Depression as well as Baseline Adverse Events} and the First Onset of MDE During Follow-up

Familial liability for depression significantly predicts incident MDE during follow-up in offspring even after adjustment for age, gender, anxiety disorders, SUD, and adverse events (OR adjusted $=2.0 ; 95 \% \mathrm{CI}=1.45-2.63 ; \mathrm{p}=.001)$. Of the respondents with familial depression liability (n 1054), 20.5\% developed an MDE compared with $10.7 \%$ of respondents without familial risk $(n=928)$.

Compared with respondents without any baseline adverse event, respondents with exposure to any adverse event prior to baseline were significantly more likely to report the first onset of MDE during follow-up (20.2\% vs. $13.1 \%$; OR $=1.8 ; 95 \% \mathrm{CI}=1.39-2.38 ; \mathrm{p}=.001)$ (Table 1 , upper part). Other adversity categories were also found to be associated with MDE with ORs ranging between 1.6 and 1.8. All associations could be replicated when additionally controlling for baseline anxiety, SUD, and familial depression liability. 
The higher the number of reported baseline adverse events, the higher was the risk for the subsequent onset of MDE (Table 1, lower part). Strongest associations were found for the number of separation events $(95 \% \mathrm{CI}=1.29-2.20 ; \mathrm{p}=.001)$ and severe traumatic events $(95 \% \mathrm{CI}=1.28-2.24 ; \mathrm{p}=.001)$ with ORs of 1.7 per increase by one event.

\section{Baseline Adverse Events and the Prediction of Incident MDE with Respect to Familial Liability for Depression}

Comparing the subgroups with and without familial liability for depression, the association pattern is considerably different. Among those with familial liability, all adverse event categories significantly predicted the onset of MDE, even when ORs were adjusted for all control variables including anxiety and SUD. In contrast, among respondents without familial liability, no associations were found (Table 2, upper part).

The same pattern was shown concerning the number of adverse events. Significant associations were revealed only in the liability subgroup where respondents who reported a higher number of events were at increased risk for MDE with the strongest association for the number of severe traumatic events $(\mathrm{OR}$ adjusted $=1.7 ; 95 \% \mathrm{CI}=1.21-2.37 ; \mathrm{p}=.002)$ (Table 2, lower part).

\section{The Interplay Between Familial Depression Liability and Adverse Events for the Prediction of $M D E$}

Table 3 illustrates the difference in incident MDE if only one of the two risk factors - familial depression liability or adverse events - was present, as well as the interaction of both factors expressed as RD. Whereas familial liability alone was consistently significant in predicting incident MDE, exposure to adverse events alone was not related to an increased risk for MDE when compared with the group with neither factor (neither liability nor adversity).

However, the model revealed additive interaction effects between familial liability and adverse events for the subsequent onset risk of MDE. This means that the sum of the RDs for the independent effects of both factors is exceeded by the joint effect of these factors in terms of the RD for interaction. For example, the RD for the group exposed to both factorsfamilial liability and any severe trauma - compared with the group exposed to neither factor significantly exceeded the sum of RDs of the single factors $(7.3 \%+5.9 \%)$ by 10.9 percentage points. Further significant RD interactions ranged between 5.9 and 11.3 percentage points. After additionally controlling for anxiety and SUD, most differences attenuated: any adverse event $(\mathrm{RD}$ adjusted $=6.9 ; 95 \% \mathrm{CI}=[-.40]-14.18 ; \mathrm{p}=.064)$, any trauma $(\mathrm{RD}$ adjusted $=8.0$; $95 \% \mathrm{CI}=[-1.34]-17.39 ; \mathrm{p}=.093)$, number of adverse events $(\mathrm{RD}$ adjusted $=5.2 ; 95 \% \mathrm{CI}=[-$ $.33]-10.77 ; \mathrm{p}=.063$ ), and the number of any trauma ( $\mathrm{RD}$ adjusted $=7.5 ; 95 \% \mathrm{CI}=[-.42]-$ $15.48 ; \mathrm{p}=.063)$. The strongest $\mathrm{RD}$ interaction appeared for the number of severe traumatic events ( $\mathrm{RD}$ adjusted $=9.2 ; 95 \% \mathrm{CI}=.95-17.54 ; \mathrm{p}=.029)$. No interaction effects were found for separation events.

Results are illustrated in Figure 1 in terms of age-dependent cumulative lifetime incidences. Highest cumulative incidences of MDE revealed for respondents with both familial liability and any adverse event prior to baseline (group 4). Cumulative incidences for group 3 (familial depression liability only) were slightly, but not significantly, higher than those for group 2 (adversity at $\mathrm{T} 0$ only) $(\mathrm{HR}=1.3 ; 95 \% \mathrm{CI}=.86-2.07 ; \mathrm{p}=.197)$. The lowest incidence curve resulted for respondents with neither liability nor adverse events (group 1), reaching at no age a level over $12 \%$. 
All adverse event categories were significantly associated with familial depression liability even after controlling for offspring's anxiety and SUD, MDE, age, and gender, with the highest OR found for separation events (OR adjusted $\quad 2.2 ; 95 \%$ CI $\quad 1.75-2.83 ; p \quad .001$ ) (Table 4, upper part). The same pattern was observed for the number of adverse events with significant associations between familial liability and all adversity categories (Table 4, lower part).

\section{Discussion}

The aim of the present investigation was to explore various processes of interplay between familial depression liability and separation and traumatic events in predicting the first onset of MDE in a family study that was based on a large community sample and a prospectivelongitudinal design over 10 years. 1) Consistent with previous reports $(51,52)$, familial depression liability and adverse events could be confirmed as risk factors for the first depression onset. 2) Additionally, we could demonstrate that the effect of adverse events on the new development of MDE was clearly evident only among those under familial risk and therefore seemed to be moderated by parental depression status. 3) Even without the occurrence of adverse events, individuals with a familial depression liability had an elevated risk of the first onset of MDE, but this was further increased by additional exposure to adverse events. Significant interactions indicate that on a familial vulnerable background, adverse, particularly traumatic events, contribute considerably to the development of depression as powerful triggers. 4) With increasing number of adverse events, the risk for the subsequent development of depression also increased in the sense of a dose-response relationship, indicating together with their temporal priority a possible causal role of adverse events. Strongest interaction effect was found for the number of severe traumatic events defined by DSM-IV A2 criterion (RD adjusted $=9.2$ ), suggesting that contextual threat may have an additional malignant impact. 5) Found effects of adverse events can be characterized as longterm vulnerabilities for MDE, as we prospectively considered their impact on the depression development over a 10-year follow-up period. 6) Respondents with familial depression liability were more likely to experience separation and traumatic events, particularly accidents (data available on request), than those without familial depression liability. 7) The above reported results do not apply to traumatic events that are only witnessed but did not affect the person directly $(n=99 ; 5.6 \%)$. Witnessing traumatic events was associated with depression onset only among respondents without familial risk (number of any witnessed event: OR adjusted $=2.2 ; 95 \% \mathrm{CI}=1.03-4.89 ; \mathrm{p}=.041)$. Neither interactions nor associations between these events and familial liability could be observed (data available on request). Accordingly, Foley et al. (11) showed that the exposure to most network events (occurring to someone in the respondent's social network) but not to personal events was mainly influenced by random factors. 8) Results could be replicated when additionally controlling for anxiety orders and SUD.

Before discussing found results, some limitations of our study should be mentioned. 1) Our family data do not allow separation of genetic factors from shared family environment with respect to the effects of familial liability. 2) In the older cohort, direct information about the parents' psychopathology was not available; in these cases, family history information was obtained from the offspring's interview. 3) The use of the prospective cohort design for the present analyses implied exclusion of individuals with lifetime MDE at baseline. This could have led to exclusion of cases with depression onset briefly after trauma exposure and thus the 
strength of the association might be affected. 4) Even if our analyses were based on a large community sample, case numbers might be still too small for detecting interaction effects (53). Thus, it seems to be justified to consider interaction effects identified with approaching significance. 5) Some events, particularly separation events, were considerably (OR adjusted $=2.0$ ) associated with familial liability. Here, the RD interaction might be biased upward. 6) We cannot exclude that familial depression liability had induced a reporting bias for adverse events.

\section{Interplay of Familial Depression Liability and Adverse Events: Mechanisms of Risk}

With these limitations in mind, we address the mechanisms of relationship between environmental and familial risk. In the present study, familial liability is assumed to be determined by genetic factors and shared family environment and therefore the following three hypothetical models could explain the results: 1) Within a genetic perspective, our results support the gene-environment interaction model in favor of a biological synergism $(41,43)$ of familial depression liability and adverse, especially traumatic events in causing first depression onset. In this context, our results are in line with findings from twin and other family studies $(7,10,24)$. 2) In addition to gene-environment interactions, we have to consider associations between a genetic and an adversity risk that could result from both being induced by a common (genetic) risk factor or that the familiality of depression is due to the familiality of events. According to a gene-environment correlation, our data show that primarily separation events (especially parental divorce) but also traumatic events (in particular accidents) are more common among individuals from depression vulnerable families, suggesting a possible influence of genetic factors on exposure to these events. These findings are again consistent with previous reports $(11,12,18)$. 3) Based on the assumption that familial depression liability resulted from shared environmental factors, we interpret the presented results as environment- environment interactions as well as correlations. On the one hand, social support may be an example for an interaction effect insofar that coping styles in healthy families could buffer the effects of adverse events. On the other hand, a low socioeconomic background could increase exposure rate to traumatic events in the sense of a correlational model.

Overall, interaction and correlational processes seem not to be exclusive but contribute concomitantly to this interplay (6). Even if gene-environment correlations are involved, exposure to events is not completely determined by genes (54). The extent to which both processes work seems to be dependent on the specific environmental pathogen (28) and on an individual's developmental stage (29).

\section{Long-Term Impact of Adverse Events on First Depression Onset}

While many studies had analyzed adverse events as direct triggers of $\operatorname{MDE}(6,10)$, it is remarkable that we could demonstrate strong effects of adversity during childhood up to young adulthood on subsequent depression onset in familial vulnerable individuals, even though we considered an extended time period of 10 years indicating medium and longterm effects of adverse events. Such long-term effects are explained, for instance, by the model of Heim et al. $(29,55,56)$ proposing that a genetic predisposition, together with early adverse experiences during sensitive developmental phases, induce a persistent vulnerability to stress effects later in life. Stress vulnerability mediated by changes in stress-responsive neurobiological systems like the hypothalamic-pituitary-adrenal axis, in turn, increases the risk to develop mood disorders. 
Studies according to an advanced genetic epidemiological paradigm like the present investigation indirectly determine genetic vulnerability by using twin and family data and thus globally estimate the kind and magnitude of a gene-environment interplay. They are effective tools to answer basic questions as, for example, which specific environmental pathogens do play a role, how do they work (e.g., short-term or prolonged effect), how does the action of these risk factors change as a function of developmental stages, what kind of interplay with a genetic vulnerability could be assumed for specific events, or how could personality traits play a role as pathways from genes to control sensitivity for stressful life events and from genes to event exposure as well, to mention only a few. This information should be combined with molecular genetic approaches investigating selected susceptibility genes to elucidate how these specific genes together with environmental factors could contribute to the development of depression $(1,57,58)$.

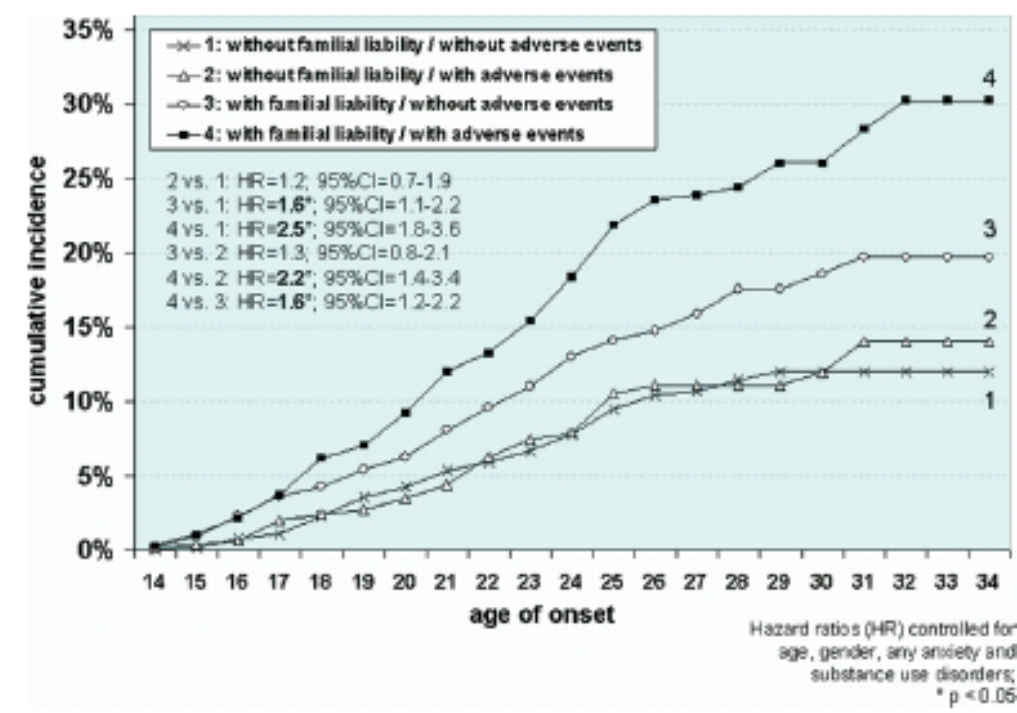

Figure 1. Cumulative Iffetime Incidences of MDE by familial depression liability and any lifetime adverse event prior to baseline. MDE, major depresslve eplsode. 
Table 1. Assoclations Between Baseline Adverse Events and First Onset of MDE During Follow-up

\begin{tabular}{|c|c|c|c|c|c|c|c|c|}
\hline \multirow[b]{3}{*}{ Lifetime Adverse Event at Baseline ${ }^{b}$} & \multicolumn{8}{|c|}{ Incident MDE ( $N-330)$ During Follow-up $\left(\mathrm{T}_{1}-\mathrm{T}_{3}\right)^{\sigma}$ Among Individuals } \\
\hline & \multicolumn{2}{|c|}{$\begin{array}{c}\text { Without Adverse } \\
\text { Event }\end{array}$} & \multicolumn{2}{|c|}{$\begin{array}{l}\text { With Adverse } \\
\text { Event }\end{array}$} & \multirow[b]{2}{*}{ OR } & \multirow[b]{2}{*}{9590} & \multirow[b]{2}{*}{ OR adj. } & \multirow[b]{2}{*}{$95 \% \mathrm{Cl}$} \\
\hline & $n$ & $96 \mathrm{w}$ & $n$ & $\%_{w}$ & & & & \\
\hline Any Adverse Event & 175 & 13.1 & 155 & 20.2 & $1.8^{d}$ & $1.39-2.38$ & $1.5^{\mathrm{d}}$ & $1.16-2.02$ \\
\hline Any separation event & 212 & 13.9 & 118 & 20.8 & $1.7^{d}$ & $1.26-2.22$ & $1 . A^{d}$ & $1.05-1.88$ \\
\hline Any trauma & 265 & 15.0 & 65 & 20.4 & $1.6^{d}$ & $1.16-2.31$ & $1 . A^{c}$ & $.98-2.00$ \\
\hline \multirow[t]{3}{*}{ Any severe trauma } & 275 & 15.0 & 55 & 22.7 & $1.8^{d}$ & $1.26-2.64$ & $1.6^{d}$ & $1.08-2.32$ \\
\hline & \multicolumn{4}{|c|}{$\begin{array}{c}\text { Mean Number of Adverse Events } \\
\text { Among Individuals }\end{array}$} & & & & \\
\hline & \multicolumn{2}{|c|}{$\begin{array}{c}\text { Without } \\
\text { Incident MDE }\end{array}$} & \multicolumn{2}{|c|}{$\begin{array}{l}\text { With Incident } \\
\text { MDE }\end{array}$} & & & & \\
\hline Number of Events ${ }^{b}$ & $\mathrm{~m}$ & $\overline{S D}$ & $\mathrm{~m}$ & $\mathrm{SD}$ & OR & $95 \% \mathrm{Cl}$ & OR adj. & $95 \% \mathrm{Cl}$ \\
\hline Number of adverse events & .45 & .66 & .68 & 85 & $1.5^{d}$ & $1.33-1.90$ & $1 . A^{d}$ & $1.18-1.71$ \\
\hline Number of separation events & 28 & .48 & 41 & .54 & $1.7^{d}$ & $1.29-2.20$ & $1.5^{d}$ & $1.11-1.92$ \\
\hline Number of traumatic events & .17 & .42 & .26 & .61 & $1.6^{d}$ & $1.23-2.07$ & $1 . A^{d}$ & $1.08-1.85$ \\
\hline Number of severe traumatic events & .12 & .37 & .22 & 57 & $1.7^{d}$ & $1.28-2.24$ & $1.5^{d}$ & $1.14-2.00$ \\
\hline \multicolumn{9}{|c|}{ 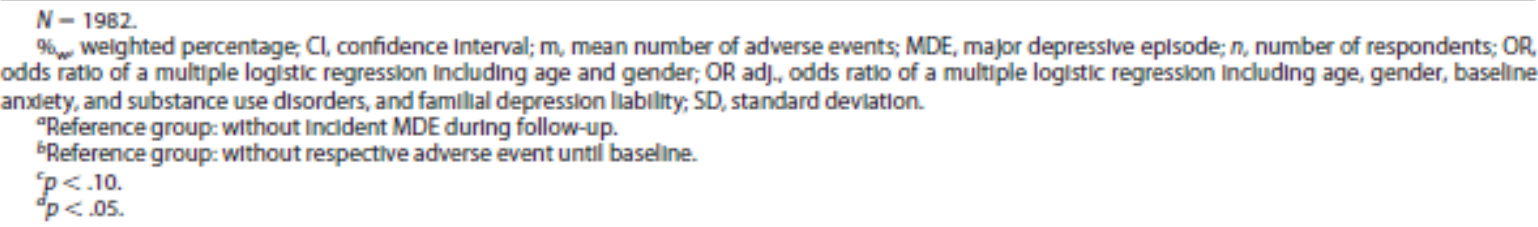 } \\
\hline
\end{tabular}

Table 2. Assoclations Between Baseline Adverse Events and Incident MDE by Famillal Depression Llability

\begin{tabular}{|c|c|c|c|c|c|c|c|c|c|c|c|c|c|c|c|}
\hline \multirow{4}{*}{$\begin{array}{l}\text { Lifetime Adverse Event } \\
\text { at Baseline }\end{array}$} & \multicolumn{15}{|c|}{ Incident MDE $(N-330)$ During Follow-up $\left(\mathrm{T}_{1}-\mathrm{T}_{3}\right)^{2}$ Among Individuals } \\
\hline & \multicolumn{8}{|c|}{ Without Famillal Llability for Depression } & \multicolumn{7}{|c|}{ With Familial Llability for Depression } \\
\hline & \multicolumn{2}{|c|}{$\begin{array}{c}\text { Without } \\
\text { Adverse } \\
\text { Event }\end{array}$} & \multicolumn{3}{|c|}{$\begin{array}{c}\text { With } \\
\text { Adverse } \\
\text { Event }\end{array}$} & \multirow{2}{*}{$\begin{array}{c}\text { OR } \\
95 \% \mathrm{Cl}\end{array}$} & \multirow{2}{*}{\multicolumn{2}{|c|}{$\begin{array}{l}\text { OR adj. } \\
95 \% \mathrm{Cl}\end{array}$}} & \multicolumn{2}{|c|}{$\begin{array}{c}\text { Without } \\
\text { Adverse } \\
\text { Event }\end{array}$} & \multicolumn{3}{|c|}{$\begin{array}{l}\text { With Adverse } \\
\text { Event } \\
\end{array}$} & \multirow{2}{*}{$\begin{array}{c}\mathrm{OR} \\
95 \% \mathrm{Cl} \\
\end{array}$} & \multirow{2}{*}{$\begin{array}{l}\text { OR adj. } \\
95 \% \text { C }\end{array}$} \\
\hline & $n$ & $\% w_{w}$ & & $n$ & $\%$ w & & & & $n$ & 96 & & $n$ & $\%_{w}$ & & \\
\hline Any Adverse Event & 71 & 10.3 & & 33 & 11.5 & $\begin{array}{c}1.2 \\
.73-1.96\end{array}$ & $\begin{array}{r}1 . \\
69-\end{array}$ & & 104 & 16 & & 122 & 25.0 & $\begin{array}{c}1.9^{f} \\
1.35-2.63\end{array}$ & $\begin{array}{c}1.8^{c} \\
1.28-2.51\end{array}$ \\
\hline Any separation event & 80 & 10.1 & & 24 & 13.0 & $\begin{array}{c}1.3 \\
.77-2.32\end{array}$ & $\begin{array}{r}1 . \\
74-\end{array}$ & & 132 & 18 & & 94 & 24.4 & $\begin{array}{c}1.6^{\varepsilon} \\
1.10-2.18\end{array}$ & $\begin{array}{c}1.5^{c} \\
1.05-2.09\end{array}$ \\
\hline Any trauma & 91 & 10.9 & & 13 & 9.5 & $\begin{array}{c}1.0 \\
.47-1.94\end{array}$ & 43 & & 174 & 19 & & 52 & 27.1 & $\begin{array}{c}1.8^{\epsilon} \\
1.18-2.68\end{array}$ & $\begin{array}{c}1 . J^{5} \\
1.09-2.51\end{array}$ \\
\hline \multirow[t]{3}{*}{ Any severe trauma } & 92 & 10.6 & & 12 & 11.4 & $\begin{array}{c}1.2 \\
.56-2.43\end{array}$ & $\begin{array}{r}1 . \\
52-\end{array}$ & & 183 & 19 & & 43 & 29.7 & $\begin{array}{c}2.0^{6} \\
1.25-3.04\end{array}$ & $\begin{array}{c}1.8^{c} \\
1.16-2.85\end{array}$ \\
\hline & & \multicolumn{5}{|c|}{$\begin{array}{c}\text { Mean Number of Events } \\
\text { Among Individuals }\end{array}$} & \multicolumn{7}{|c|}{$\begin{array}{c}\text { Mean Number of Events } \\
\text { Among Individuals }\end{array}$} & & \\
\hline & & \multicolumn{3}{|c|}{$\begin{array}{l}\text { Without } \\
\text { MDE }\end{array}$} & \multicolumn{2}{|c|}{ With MDE } & \multirow{2}{*}{$\begin{array}{c}\mathrm{OR} \\
95 \% \mathrm{Cl}\end{array}$} & \multirow{2}{*}{\multicolumn{2}{|c|}{$\begin{array}{l}\text { OR adj. } \\
9596 \mathrm{Cl}\end{array}$}} & $\begin{array}{r}\text { Wit } \\
\mathrm{M}\end{array}$ & & Wit & h MDE & OR & OR adj. \\
\hline \multicolumn{3}{|l|}{ Number of events ${ }^{b}$} & $\mathrm{~m}$ & SD & $\mathrm{m}$ & SD & & & & $\mathrm{m}$ & SD & $\mathrm{m}$ & SD & $95 \% \mathrm{Cl}$ & $95 \% \mathrm{C}$ \\
\hline \multicolumn{3}{|l|}{ Number of Adverse Events } & 35 & .59 & .40 & .65 & $\stackrel{12}{80-1.79}$ & & & .56 & .70 & 80 & .89 & $\begin{array}{c}1.6^{6} \\
1.29-1.97\end{array}$ & $\begin{array}{c}1.6^{6} \\
1.25-1.92\end{array}$ \\
\hline \multicolumn{3}{|c|}{ Number of separation events } & 20 & .43 & .26 & 48 & $\begin{array}{c}1.3 \\
.79-2.25\end{array}$ & & $\begin{array}{l}3 \\
2.16\end{array}$ & .36 & .50 & .48 & .56 & $\begin{array}{c}1.6^{\varepsilon} \\
1.17-2.24\end{array}$ & $\begin{array}{c}1.6^{\varepsilon} \\
1.12-2.17\end{array}$ \\
\hline \multicolumn{3}{|c|}{ Number of traumatic events } & .14 & .39 & .13 & .39 & $\begin{array}{c}1.0 \\
52-2.02\end{array}$ & & & .19 & .45 & .32 & .67 & $\begin{array}{c}1.7^{5} \\
1.23-2.24\end{array}$ & $\begin{array}{c}1.6^{c} \\
1.16-2.14\end{array}$ \\
\hline \multicolumn{3}{|c|}{ Number of severe traumatic events } & .11 & .34 & .10 & .31 & $\begin{array}{c}1.0 \\
56-1.93\end{array}$ & & & .14 & .39 & .28 & .65 & $\begin{array}{c}1.8^{\varepsilon} \\
1.28-2.49\end{array}$ & $\begin{array}{c}1.7^{c} \\
1.21-2.37\end{array}$ \\
\hline
\end{tabular}

$N=1982$.

96 weighted percentage; $\mathrm{Cl}$, confidence Interval; $\mathrm{m}$, mean number of adverse events; MDE, major depressive eplsode; $n$, number of respondents; OR, odds ratio of a multiple regression including age and gender; $O R$ adj, odds ratio of a multiple logistic regression including age, gender, baseline anxlety, and substance use dlsorders; SD, standard devlation.

aReference group: without Incident MDE during follow-up.

'Reference group: without respectlve adverse event until baseline.

${ }^{c} p<.05$. 
Table 3. Additive Interactions Between Famillal Depression Llability and Adverse Events

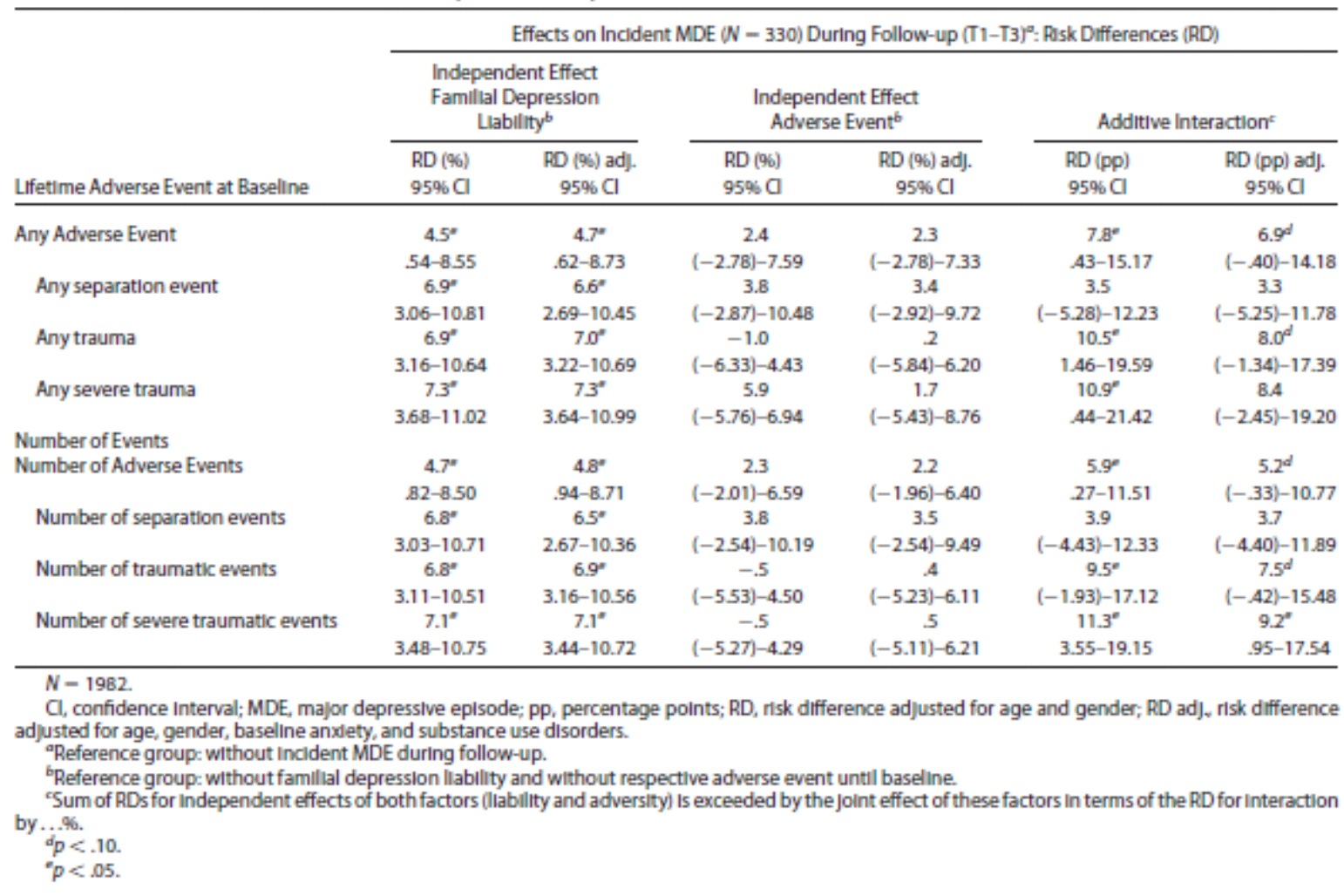

Table 4. Assocations Between Baseline Adverse Events and Famillial Depression Llability

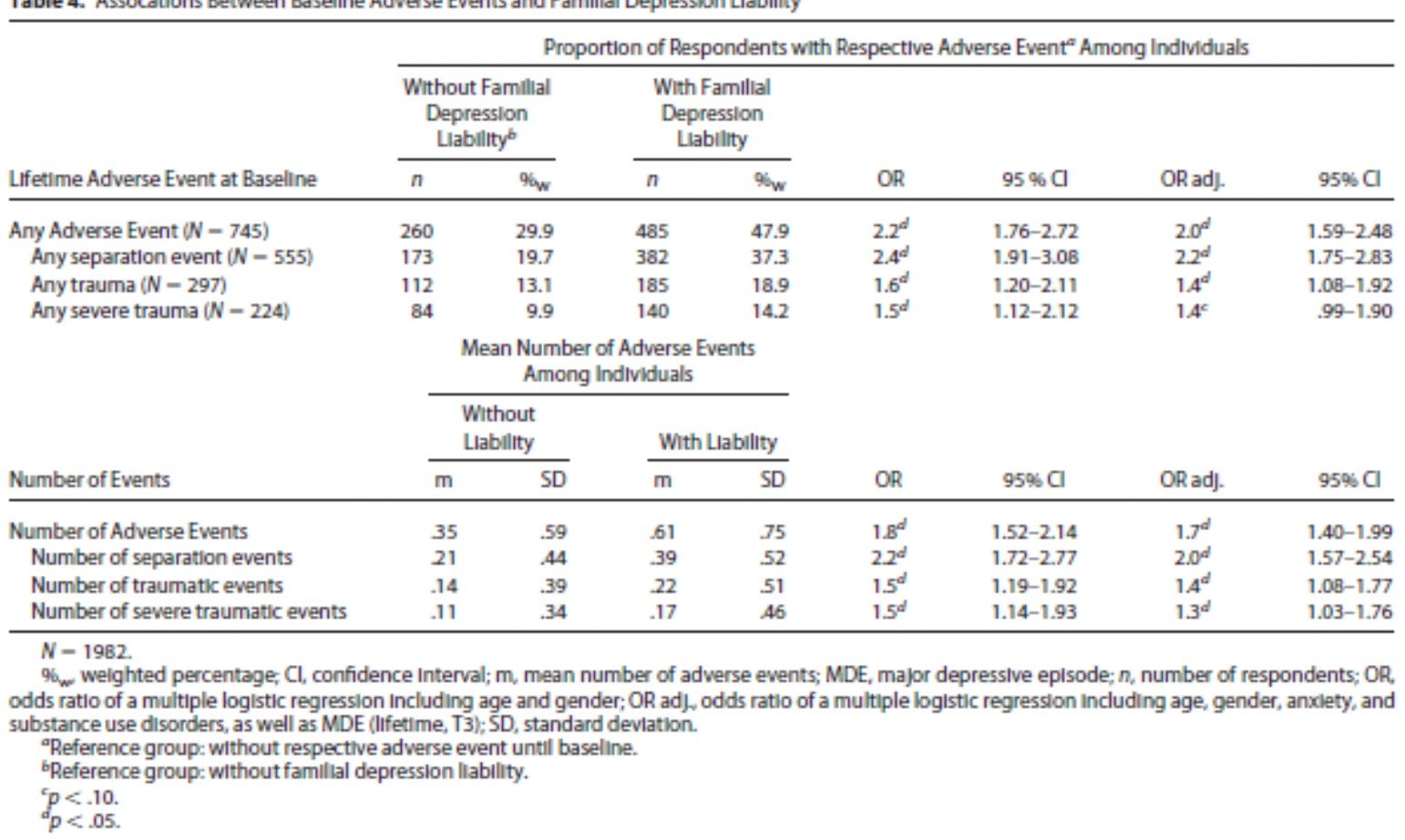

This work is part of the Early Developmental Stages of Psychopathology Study and is funded by the German Federal Ministry of Education and Research project no. 01EB9405/6, 01EB 9901/6, EB01016200, 01EB0140, and 01EB0440. Part of the field work and analyses were also additionally supported by Grants of the Deutsche Forschungsgemeinschaft LA1148/1-1, 
WI2246/1-1, WI 709/7-1, and WI 709/8-1. Principal investigators are Dr. Hans-Ulrich Wittchen and Dr. Roselind Lieb.

Core staff members of the Early Developmental Stages of Psychopathology group are: Dr. Kirsten von Sydow, Dr. Gabriele Lachner, Dr. Axel Perkonigg, Dr. Peter Schuster, Dipl.-Stat. Michael Höfler, Dipl.-Psych. Holger Sonntag, Dr. Tanja Brückl, Dipl.-Psych. Elzbieta Garczynski, Dr. Barbara Isensee, Dipl.- Psych. Agnes Nocon, Dr. Chris Nelson, Dipl.-Inf. Hildegard Pfister, Dr. Victoria Reed, Dipl.-Soz. Barbara Spiegel, Dr. Andrea Schreier, Dr. Ursula Wunderlich, Dr. Petra Zimmermann, Dr. Katja Beesdo, and Dr. Antje Bittner. Scientific advisors are Dr. Jules Angst (Zurich), Dr. Jürgen Margraf (Basel), Dr. Günther Esser (Potsdam), Dr. Kathleen Merikangas (National Institute of Mental Health, Bethesda), Dr. Ron Kessler (Harvard, Boston), and Dr. Jim van Os (Maastricht).

We thank Dr. Andrea Schreier for her helpful comments as well as Dipl.-Stat. Michael Höfler for statistical advisory.

Disclosures: Petra Zimmermann: Research assistant in the research group Molecular Psychology at the Max-Planck Institute of Psychiatry, Munich, Germany. Grant/Research support: German Federal Ministry of Education and Research. Consultant: none. Speakers bureau: none. Major stockshare holder: none. Other: none.

Tanja Brückl: Research assistant in the research group Molecular Psychology at the MaxPlanck Institute of Psychiatry, Munich, Germany. Grant/Research support: none. Consultant: none. Speakers bureau: none. Major stockshare holder: none. Other: none.

Roselind Lieb: Chair of the Epidemiology and Health Psychology Unit at the University of Basel, Switzerland. Grant/Research support: German Federal Ministry of Education and Research. Consultant: none. Speakers bureau: Wyeth. Major stockshare holder: none. Other: none.

Agnes Nocon: Research assistant in the research group Molecular Psychology at the MaxPlanck Institute of Psychiatry, Munich, Germany. Grant/Research support: none. Consultant: none. Speakers bureau: none. Major stockshare holder: none. Other: none.

Marcus Ising: Head of the research group Molecular Psychology at the Max-Planck Institute of Psychiatry, Munich, Germany. Grant/Research support: none. Consultant: none. Speakers bureau: none. Major stockshare holder: none. Other: none. Katja Beesdo: Research assistant at the Institute of Clinical Psychology and Psychotherapy at the Technical University of Dresden, Germany. Grant/Research support: German Federal Ministry of Education and Research. Consultant: none. Speakers bureau: Pfizer. Major stockshare holder: none. Other: none.

Hans-Ulrich Wittchen: Director, Institute of Clinical Psychology and Psychotherapy, Technische Universitaet Dresden, Germany. Grant/Research support: see acknowledment, other grants unrelated to the paper: Eli Lilly and Company; Novartis; Pfizer; ScheringPlough. Consultant: Eli Lilly; Glaxo-SmithKline Pharmaceuticals; Hoffmann-La Roche Pharmaceuticals; Novartis; Pfizer; Wyeth. Speakers bureau: Novartis; Schering-Plough; Pfizer; Wyeth. Major stockshare holder: none. Other: none. 
1. Caspi A, Sugden K, Moffitt TE, Taylor A, Craig IW, Harrington H, et al. (2003): Influence of life stress on depression: Moderation by a polymorphism in the 5-HTT gene. Science 301:386-389.

2. Gillespie NA, Whitfield JB, Williams B, Heath AC, Martin NG (2005): The relationship between stressful life events, the serotonin transporter (5-HTTLPR) genotype and major depression. Psychol Med 35:101-111.

3. Surtees PG, Wainwright NW, Willis-Owen SA, Luben R, Day NE, Flint J (2006): Social adversity, the serotonin transporter (5-HTTLPR) polymorphism and major depressive disorder. Biol Psychiatry 59:224 -229.

4. Plomin R, Defries JC, Loehlin JC (1977): Genotype-environment interaction and correlation in analysis of human-behavior. Psychol Bull 84:309-322.

5. Rutter M, Silberg J (2002): Gene-environment interplay in relation to emotional and behavioral disturbance. Annu Rev Psychol 53:463- 490.

6. Eaves L, Silberg J, Erkanli A (2003): Resolving multiple epigenetic pathways to adolescent depression. J Child Psychol Psychiatry 44:1006-1014.

7. Silberg J, Rutter M, Neale M, Eaves L (2001): Genetic moderation of environmental risk for depression and anxiety in adolescent girls. Br J Psychiatry 179:116-121.

8. Rice F, Harold GT, Shelton KH, Thapar A (2006): Family conflict interacts with genetic liability in predicting childhood and adolescent depression. J Am Acad Child Adolesc Psychiatry 45:841- 848.

9. Kendler KS, Kessler RC, Neale MC, Heath AC, Eaves LJ (1993): The prediction of major depression in women: Toward an integrated etiologic model. Am J Psychiatry 150:1139-1148.

10. Kendler KS, Kessler RC, Walters EE, Maclean C, Neale MC, Heath AC, et al. (1995): Stressful life events, genetic liability, and onset of an episode of major depression in women. Am J Psychiatry 152:833-842.

11. Foley DL, Neale MC, Kendler KS (1996): A longitudinal study of stressful life events assessed at interview with an epidemiological sample of adult twins: The basis of individual variation in event exposure. Psychol Med 26:1239-1252.

12. Kendler KS, Karkowski-Shuman L (1997): Stressful life events and genetic liability to major depression: Genetic control of exposure to the environment. Psychol Med 27:539 -547.

13. Lyons MJ, Goldberg J, Eisen SA, True W, Tsuang MT, Meyer JM, et al. (1993): Do genes influence exposure to trauma? A twin study of combat. Am J Med Genet 48:22-27.

14. Plomin R, Pedersen NL, Lichtenstein P, Mcclearn GE, Nesselroade JR (1990): Genetic influence on life events during the last half of the lifespan. Psychol Aging 5:25-30.

15. Thapar A, McGuffin P (1996): Genetic influences on life events in childhood. Psychol Med 26:813-820.

16. Drieling T, van Calker D, Hecht H (2006): Stress, personality and depressive symptoms in a 6.5 year follow-up of subjects at familial risk for affective disorders and controls. J Affect Disord 91:195203.

17. Hillegers MH, Burger H, Wals M, Reichart CG, Verhulst FC, Nolen WA, et al. (2004): Impact of stressful life events, familial loading and their interaction on the onset of mood disorders: Study in a high-risk cohort of adolescent offspring of parents with bipolar disorder. Br J Psychiatry 185:97-101. 18. McGuffin P, Katz R, Bebbington P (1988): The Camberwell Collaborative Depression Study. III. Depression and adversity in the relatives of depressed probands. Br J Psychiatry 152:775-782.

19. Pollit J (1972): The relationship between genetic and precipitating factors in depressive illness. $\mathrm{Br}$ J Psychiatry 121:67-70.

20. Wals M, Hillegers MHJ, Reichart CG, Verhulst FC, Nolen WA, Ormel J (2005): Stressful life events and onset of mood disorders in children of bipolar parents during 14-month follow-up. J Affect Disord 87:253-263.

21. Farmer A, Harris T, Redman K, Sadler S, Mahmood A, McGuffin P (2000): Cardiff depression study. A sib-pair study of life events and familiality in major depression. Br J Psychiatry 176:150 155.

22. Farmer AE, McGuffin P (2003): Humiliation, loss and other types of life events and difficulties: A comparison of depressed subjects, healthy controls and their siblings. Psychol Med 33:1169 -1175. 23. Perris H, Vonknorring L, Perris C (1982): Genetic vulnerability for depression and life events. Neuropsychobiology 8:241-247. 
24. Eley TC, Liang HL, Plomin R, Sham P, Sterne A, Williamson R, et al. (2004): Parental familial vulnerability, family environment, and their interactions as predictors of depressive symptoms in adolescents. J Am Acad Child Adolesc Psychiatry 43:298 -306.

25. Fendrich M, Warner V, Weissman MM (1990): Family risk-factors, parental depression, and psychopathology in offspring. Dev Psychol 26:40-50.

26. Hammen C, Shih J, Altman T, Brennan PA (2003): Interpersonal impairment and the prediction of depressive symptoms in adolescent children of depressed and nondepressed mothers. J Am Acad Child Adolesc Psychiatry 42:571-577.

27. Hoffmann JP, Baldwin SA, Cerbone FG (2003): Onset of major depressive disorder among adolescents. J Am Acad Child Adolesc Psychiatry 42:217-224.

28. Moffitt TE, Caspi A, Rutter M (2003): Strategy for investigating interactions between measured genes and measured environments. Arch Gen Psychiatry 62:473- 481.

29. Heim C, Plotsky PM, Nemeroff CB (2004): Importance of studying the contributions of early adverse experience to neurobiological findings in depression. Neuropsychopharmacology 29:641648.

30. Kendler KS, Kuhn JW, Prescott CA (2004): Childhood sexual abuse, stressful life events and risk for major depression in women. Psychol Med 34:1475-1482.

31. Lieb R, Isensee B, Sydow von K, Wittchen HU (2000): The Early Developmental Stages of Psychopathology Study (EDSP): A methodological update. Eur Addict Res 6:170 -182.

32. Wittchen HU, Perkonigg A, Lachner G, Nelson CB (1998): Early Developmental Stages of Psychopathology Study (EDSP): Objectives and design. Eur Addict Res 4:18 -27.

33. Lachner G, Wittchen HU(1997): Münchner Composite International Diagnostic Interview, M-

CIDI (familiengenetische Version). Elternbefragung, Version 2.0. Munich: Max-Planck-Institut für Psychiatrie/Eigendruck.

34. Lieb R, Isensee B, Hofler M, Pfister H, Wittchen HU (2002): Parental major depression and the risk of depression and other mental disorders in offspring: A prospective-longitudinal community study. Arch Gen Psychiatry 59:365-374.

35. Wittchen HU, Pfister H (1997): DIAX-Interviews: Manual für Screening-Verfahren und Interview; Interviewheft Längsschnittuntersuchung (DIAX-Lifetime); Ergänzungsheft (DIAX-Lifetime);

Interviewheft Querschnittuntersuchung (DIAX-12 Monate); Ergänzungsheft (DIAX-12 Monate); PCProgramm zur Durchführung des Interviews (Längs- und Querschnittuntersuchung);

Auswertungsprogramm. Frankfurt, Germany: Swets \& Zeitlinger.

36. American Psychiatric Association (1994): Diagnostic and Statistical Manual of Mental Disorders, 4th ed. Washington, DC: American Psychiatric Association.

37. Lachner G, Wittchen HU, Perkonigg A, Holly A, Schuster P, Wunderlich U, et al. (1998):

Structure, content and reliability of the Munich Composite International Diagnostic Interview (MCIDI) substance use sections. Eur Addict Res 4:28-41.

38. Reed V, Gander F, Pfister H, Steiger A, Sonntag H, Trenkwalder C, et al. (1998): To what degree the Composite International Diagnostic Interview (CIDI) correctly identifies DSM-IV disorders?

Testing validity issues in a clinical sample. Int J Methods Psychiatr Res 7:142-155.

39. Wittchen HU, Lachner G, Wunderlich U, Pfister H (1998): Test-retest reliability of the computerized DSM-IV version of the Munich Composite International Diagnostic Interview (MCIDI). Soc Psychiatry Psychiatr Epidemiol 33:568 -578.

40. Merikangas KR, Stevens DE, Fenton B, Stolar M, O’Malley S, Woods SW, et al. (1998): Comorbidity and familial aggregation of alcoholism and anxiety disorders. Psychol Med 28:773-788. 41. Darroch J (1997): Biologic synergism and parallelism. Am J Epidemiol 145:661- 668.

42. Henquet C, Krabbendam L, Spauwen J, Lieb R, Wittchen HU, van Os J (2004): Biological synergism between cannabis use and psychosis liability in young people. Acta Psychiatr Scand 110:53-54.

43. van Os J, Pederson CB, Mortensen PB (2004): Confirmation of synergy between urbanicity and familial liability in the causation of psychosis. Am J Psychiatry 161:2312-2314.

44. Greenland S (1993): Basic problems in interaction assessment. Environ Health Perspect 101(suppl 4):59-66.

45. Höfler M (2005): Causal inference based on counterfactuals. BMC Med Res Methodol 5:28.

46. Rothman KJ, Greenland S (1998): Modern Epidemiology, 2nd ed. Philadelphia: Lippincott

Williams \& Wilkins. 
47. Joffe MM, Greenland S (1995): Standardized estimates from categorical regression-models. Stat Med 14:2131-2141.

48. Thernau TM, Grambsch PM (2000): Modeling Survival Data: Extending the Cox Model (Statistics for Biology and Health). New York: Springer.

49. StataCorp LP (2006): Stata/SE 9.2 for Windows [computer program]. College Station, TX: StataCorp.

50. Royall S (1993): Model robust confidence intervals using maximum likelihood estimators. Int Stat Rev 54:142-155.

51. Kessler RC (1997): The effects of stressful life events on depression. Annu Rev Psychol 48:191214.

52. Sullivan PF, Neale MC, Kendler KS (2000): Genetic epidemiology of major depression: Review and meta-analysis. Am J Psychiatry 157:1552-1562.

53. Wachs TD, Plomin R, editors (1991): Conceptualization and Measurement of Organism-

Environment Interaction. Washington, DC: American Psychological Association.

54. Kendler KS, Karkowski L, Prescott CA (1999): The assessment of dependence in the study of stressful life events: Validation using a twin design. Psychol Med 29:1455-1460.

55. Heim C, Nemeroff CB (2001): The role of childhood trauma in the neurobiology ofmoodand anxiety disorders: Preclinical and clinical studies. Biol Psychiatry 49:1023-1039.

56. Heim C, Nemeroff CB (1999): The impact of early adverse experiences on brain systems involved in the pathophysiology of anxiety and affective disorders. Biol Psychiatry 46:1509-1522.

57. Jacobs N, Kenis G, Peeters F, Derom C, Vlietinck R, van Os J (2006): Stress-related negative affectivity and genetically altered serotonin transporter function: Evidence of synergism in shaping risk of depression. Arch Gen Psychiatry 63:989 -996.

58. Kendler KS, Kuhn JW, Vittum J, Prescott CA, Riley B (2005): The interaction of stressful life events and a serotonin transporter polymorphism in the prediction of episodes of major depression: A replication. Arch Gen Psychiatry 62:529-535. 